\title{
Jorge Pinto Ribeiro: a True Icon of Exercise Physiology and Cardiology
}

\author{
Ricardo Stein ${ }^{(1)}$ \\ Universidade Federal do Rio Grande do Sul, Porto Alegre, RS - Brazil
}

The initiative to make an edition dedicated to a certain area of knowledge in a scientific journal is always a major challenge full of hard work. Original articles, reviews and / or special cases in the field are expected and the best experts in the subject are those that the editor hopes to be able to count. This edition of the International Journal of Cardiology Science, headed by Dr. Claúdio Gil Soares de Araújo, is focused on physical exercise and its pages contain different articles on the matter. Probably, I was invited to contribute because I work and publish in the sports and exercise cardiology field, besides the fact that I am the Associate-Editor for exercise and rehabilitation of the Arquivos Brasileiros de Cardiologia. By the way, when the invitation letter arrived, I immediately accepted it, but wondered what my ideal contribution might be. Thus, over five days I glimpsed different possibilities, until one early morning, while running an insight came: Jorge Pinto Ribeiro!!! Nothing is fairer to remember than a professor and scientist with more than 150 publications, at least half of them in the exercise physiology/cardiology area. So, with the support of the International Journal of Cardiology Science Editors I was able to go through a few lines with a sense of affection and sadness, as long as many years have passed since this cardiology "giant" passed way. It is amazing to mention that, despite the hiatus of more than 6 years since his death, he continues to publish: at least three articles with his name can be found at Pubmed in the year 2018... and $\mathrm{two}^{1,2}$ in this Edition!!! Well, but who was the Jorge Pinto Ribeiro I met? The differential started with the name. At least for me an affirmative name. A name that always sounded strong, announcing that behind these 17 letters, Jorge Pinto

\section{Keywords}

Exercise/physiology; Sports/trends; Cardiac Rehabilitation/trends; Exercise Therapy.
Ribeiro, came a winner. No, actually, he was a champion. A champion at home, at work, at leisure, a blessed champion with unified qualities in a rare individual, a true winner. A man who was always offering the hand to help others on their achievements. Yes, he was the owner of this name, a person who at the height of his 57 years, in the distant year of 2012, left us. Indeed, after a Herculean fight against a rare disease, the flame of his intense and successful life was extinguished. Actually, his early departure left an enormous emptiness and deep longing in relatives, friends, colleagues, students and patients. However, we who know him well always remember his energy, his production, his life as a husband, father, brother, doctor, teacher... as a friend!!! Is evident, he was a man who lived the life. In short, as a brilliant cardiologist and one of the most talented scientists in exercise physiology/cardiology ever, Jorge Pinto Ribeiro certainly is reading the International Journal of Cardiology Science pages delighted and smiling.

Ricardo "Pinto Ribeiro" Stein

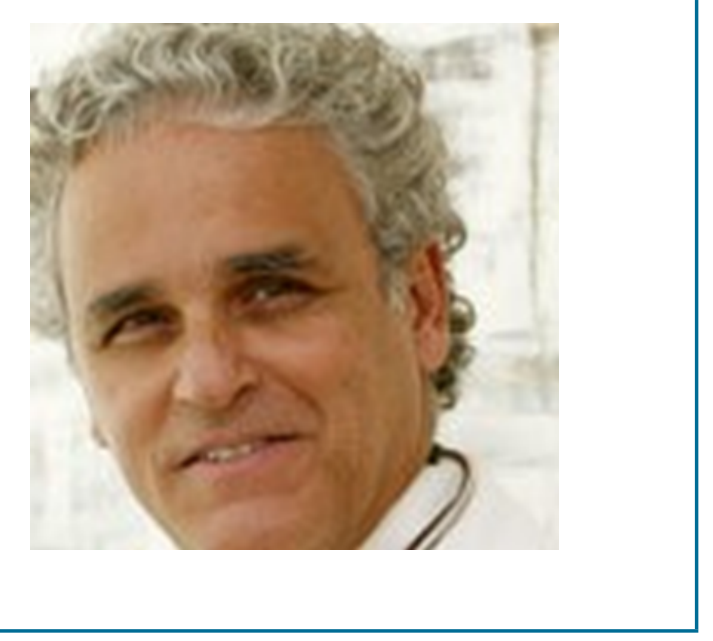




\section{Author contributions}

Conception and design of the research: Stein R. Acquisition of data: Stein R. Analysis and interpretation of the data: Stein R. Statistical analysis: Stein R. Obtaining financing: Stein R. Writing of the manuscript: Stein R. Critical revision of the manuscript for intellectual content: Stein R.

\section{Potential Conflict of Interest}

No potential conflict of interest relevant to this article was reported.

\section{References}

1. Belli KC, Silva PF, Franzoni LT, Myers J, Stein R, Ribeiro JP (In Memoriam). Speed and Grade Increment During Cardiopulmonary Treadmill Testing: Impact on Exercise Prescription. Int J Cardiovasc Sci. 2019;32(4):374-383.

\section{Sources of Funding}

There were no external funding sources for this study.

\section{Study Association}

This study is not associated with any thesis or dissertation work.

\section{Ethics approval and consent to participate}

This article does not contain any studies with human participants or animals performed by any of the authors.

2. Almeida AEM, Santander IRM, Campos MIM, Garcia JRA, Nascimento JA, Ritt LEF, et al. Classification system for cardiorespiratory fitness based on a sample of the Brazilian population. Int J Cardiovasc Sci. 2019;32(4):343-354. 